\title{
Association between biomass fuel use and the risk of cognitive impairment among older populations in China: a population- based cohort study
}

\author{
Min Du', Liyuan $\mathrm{TaO}^{2}$, Lin Zhu ${ }^{3}$ and Jue $\mathrm{Liu}^{1^{*}}$ (D)
}

\begin{abstract}
Background: Cohort studies on the impact of biomass fuel use for cooking on cognitive impairment among older population are still lacking in China and elsewhere. The aim of this study was to examine whether biomass fuel use for cooking is associated with cognitive impairment in Chinese adults aged 65 years or older.

Methods: The prospective population-based cohort study of the Chinese Longitudinal Healthy Longevity Survey (CLHLS) included participants aged 65 years or older in 2014 who were followed-up until 2018 in 23 provinces in China. The Mini-Mental State Examination (MMSE) was used to assess cognitive function, and cognitive impairment was defined as total MMSE scores less than 18. The association between biomass fuel use and cognitive impairment was evaluated using the Cox proportional hazards model.

Results: Of the 4145 participants included at baseline, participants who reported that they used biomass fuel for cooking (40.43\%; IR: 3.11 versus 2.77 per 100 person-years; aHR: 1.27, 95\% Cl: 1.02-1.58) had a higher risk of cognitive impairment compared with participants who used clean fuels (53.75\%). A stratified analyses showed greater effect estimates of cognitive impairment in the older people that lived in the rural areas (aHR: 1.444, 95\% Cl: 1.08-3.90) and never smoked (aHR: 1.33, 95\% Cl: 1.04-1.71).

Conclusions: These findings demonstrated that biomass fuel used for cooking was associated with cognitive impairment, as defined by MMSE, in a population-based study of elderly in China. To prevent cognitive impairment, the structure of cooking fuels requires improvements.
\end{abstract}

Keywords: Biomass fuel, Cognitive impairment, Chinese, Elderly, Cohort study

\section{Background}

Although clean fuels for cooking have been recommended in recent years, globally, $80 \%$ of the rural population and $<15 \%$ of the urban population still lack access to clean cooking [1]. Furthermore, biomass fuel use has

\footnotetext{
* Correspondence: jueliu@bjmu.edu.cn

'Department of Epidemiology and Biostatistics, School of Public Health, Peking University, No.38, Xueyuan Road, Haidian District, Beijing 100191 China

Full list of author information is available at the end of the article
}

been linked to household air pollution (HAP) with a higher component of particulate matter (PM) compared with the combination of biomass \& liquefied petroleum gas (LPG) and LPG [2]. Studies have reported that particulate pollution from kitchens was higher when people used biomass fuels, including charcoal, wood, and grass, compared with clean fuels, including electricity and liquefied petroleum gas [3, 4]. HAP from the burning of biomass fuels affects approximately three billion individuals worldwide $[1,5]$. Importantly, older people's frail

(C) The Author(s). 2021 Open Access This article is licensed under a Creative Commons Attribution 4.0 International License, which permits use, sharing, adaptation, distribution and reproduction in any medium or format, as long as you give appropriate credit to the original author(s) and the source, provide a link to the Creative Commons licence, and indicate if changes were made. The images or other third party material in this article are included in the article's Creative Commons licence, unless indicated otherwise in a credit line to the material. If material is not included in the article's Creative Commons licence and your intended use is not permitted by statutory regulation or exceeds the permitted use, you will need to obtain permission directly from the copyright holder. To view a copy of this licence, visit http://creativecommons.org/licenses/by/4.0/. The Creative Commons Public Domain Dedication waiver (http://creativecommons.org/publicdomain/zero/1.0/) applies to the data made available in this article, unless otherwise stated in a credit line to the data. 
health status may be easily affected by HAP. According to the 2016 global burden disease study, lower respiratory infections caused 1,080,958 deaths among adults older than 70 years old in 2016, and HAP may have been the primary cause [6]. Many studies have revealed that HAP not only had an effect on respiratory diseases including breathlessness, asthma, and even lung cancer [7], but also heart health, including elevated blood pressures and heart rates among elderly people [8]. Recently, one study reported that solid fuels used for cooking significantly increased the possibility and exacerbation of chronic lung diseases and heart diseases of the elderly in rural China [9]. Thus, the burning of biomass fuels on the health outcomes of older people requires more attention due to the higher HAP levels.

Cognitive impairment means that a person has problems with remembering, learning new things, concentrating, or making decisions, which all affect quality of life [10]. With rapid population aging, one national study estimated that the prevalence of cognitive impairment was 9\% among Chinese older persons in 2011, which was higher than most countries of the world [11]. Growing evidence suggests that air pollution has an negative effect on cognition among older adults. In addition, studies have primarily explored the association between HAP and respiratory and cardiovascular disease among older adults, but the effects of indoor combustion of biomass fuel for cooking on the central nervous system have not been broadly recognized among older adults. A cross-sectional study found that the combustion of wood or coal fuels was associated with poorer cognitive performance after adjusting for demographic, household, health, and economic characteristics among adults aged over 50 years old in Mexico [12]. Cao et al. found that solid cooking fuel use was associated with a greater decline in cognitive score overall, especially for episodic memory, according to follow-up studies that included 8397 middle-aged and older participants [13]. However, a prospective cohort study on the association of biomass fuel use for cooking with cognitive impairment among Chinese older people was limited.

Biomass fuel use for cooking is the primary source of HAP, however, the role of biomass fuel use in cognitive impairment has not been well elaborated. A large multicenter cohort study of the association between biomass fuel use and cognition in older adults is required for earlier intervention to improve mental health. Moreover, the current available studies did not control for other confounders, including exercise [14], diet [15], and other factors that could have an effect on cognition. Based on previous theory and empirical research, the aim of this study was to assess the association between biomass fuel use for cooking and the risk of cognition impairment among Chinese elderly people in a nationwide prospective cohort study.

\section{Methods}

\section{Study design and participants}

In this study, data obtained from the Chinese Longitudinal Healthy Longevity Survey (CLHLS), which is an ongoing, prospective cohort study that covered 23 out of 31 provinces in China, was analyzed. This study was established in 1998, with subsequent follow-up and recruitment of new participants in 2000, 2002, 2005, 2008, 2011, 2014, and 2018. Information regarding the health and life situations of individuals aged 65 and older were provided in the CLHLS, and more details of the study have been described elsewhere [16]. The present analysis included data from the seventh wave of the CLHLS in 2014 (at baseline), which included the question "Which fuels are normally used for cooking in your home?" The follow-up survey was conducted in 2018. The CLHLS was approved by the Ethical Review Committee of Peking University (IRB00001052-13074). All of the participants signed an informed consent at the time of participation. The research was performed in accordance with the Declaration of Helsinki.

The 2014 survey wave included 7192 Chinese elderly individuals. Participants that were excluded were 85 participants that were younger than 65 years old, 313 participants that were missing data on cooking fuels, 1370 participants that were lost to follow-up in 2018, 1181 participants that had baseline cognitive impairments, and 16 participants with missing data on the baseline MMSE scores. Furthermore, 82 participants were excluded that did not have complete MMSE score information upon the first follow-up survey. Hence, a total of 4145 participants were finally included. Figure 1 shows the full inclusion and exclusion process of the research participants in this study.

\section{Assessment of biomass fuel use for cooking}

The participant's household exposure to cooking fuels was assessed using a questionnaire that was answered at baseline by the participants that contained the question "Which fuels are normally used for cooking in your home?" The cooking fuels were categorized as biomass fuels (charcoal, firewood/straw), clean fuels (electricity, gas, solar energy), never cooked in the home, and others (e.g., fuel oil, coal, and others).

\section{Outcome}

The CLHLS participants' cognitive function was measured using the widely used screening tool called the Chinese version of the Mini-Mental State Examination (MMSE) that consisted of 11 questions covering orientation, registration, attention, calculation ability, recall, and language ability. This tool was used in 2014 and 2018 at two time points [17]. Several items on the Chinese version of the MMSE were changed based the 


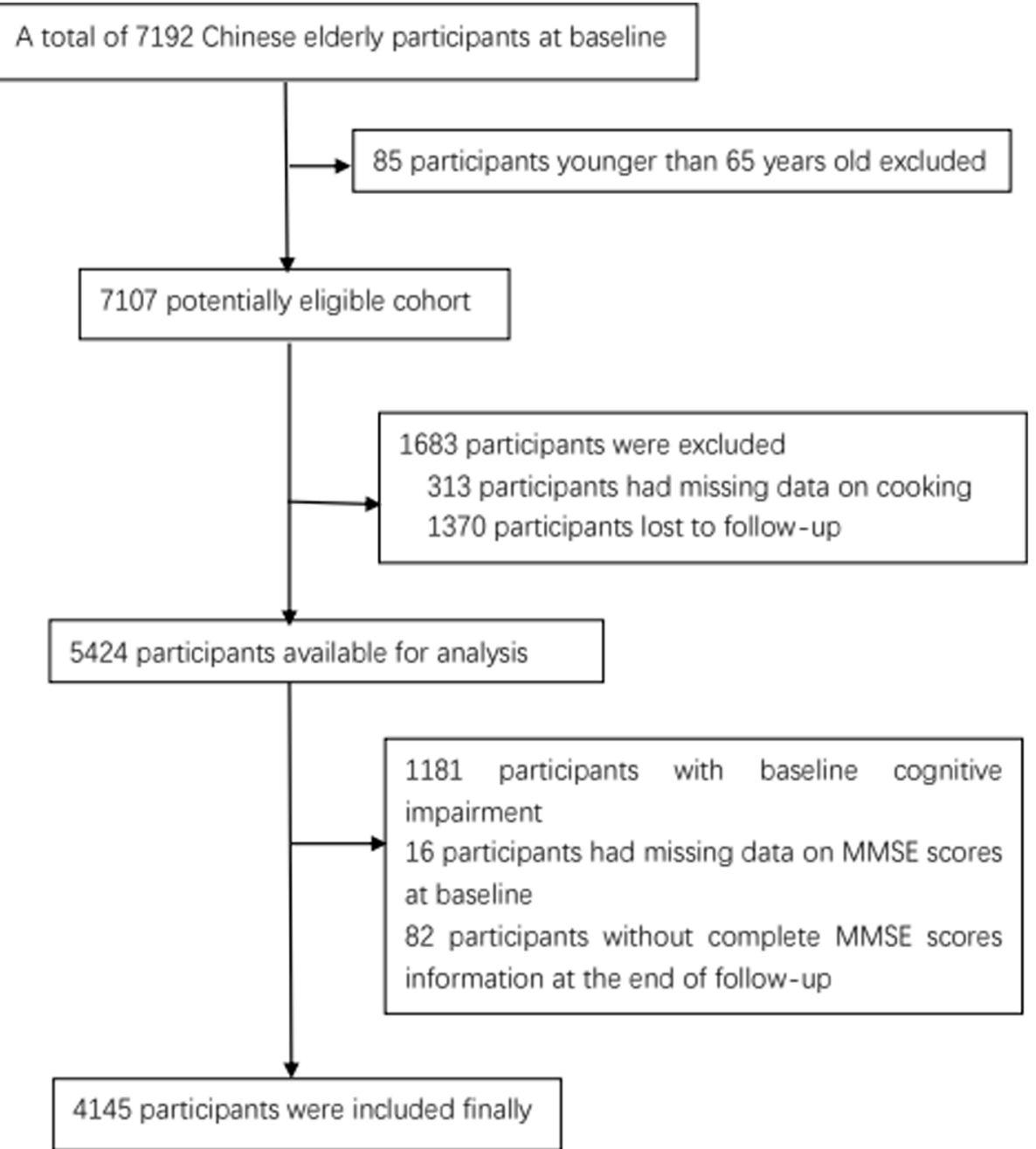

Fig. 1 The full inclusion and exclusion process of the research

cultural contexts of China, and the validity and reliability was still good [18]. All of questions were answered by the respondents without a proxy. The total MMSE scores ranged from 0 to 30 , and cognitive impairment was defined as a total MMSE score less than 18, whereas a participant with a score of 18 or higher was classified as having no cognitive impairment $[18,19]$.

\section{Covariates}

We attempted to examine as many factors as possible that have been found to be associated with fuel use for cooking and cognitive impairment [14, 15]. Trained investigators collected information, including demographic characteristics, lifestyle habits, and health status, using a standardized questionnaire. All of the surveys were face-to-face interviews conducted at the participant's home. If participants were illiterate, investigators helped them to complete the questionnaire. Details of the sample design had been described elsewhere, and the data quality was reported to be generally good [20]. Demographic characteristics included age (65-74, $75-84$, and $\geq 85$ years old), sex (male/female), education (no school/1 year or more), residence (urban/rural), household income (<10,000/10001-30,000/>30,000 yuan), and marital status (unmarried/married/divorced/widowed). Lifestyle habits included smoking status (non-smoker/smoker), drinking status (non-drinker/drinker), regular exercise (yes/no), ventilation of the kitchen when cooking at home (no ventilation/kitchen ventilation or fan/opening a window/unknown), and diet of fresh fruit (almost or quite often/occasionally/ rarely or never) and vegetables (almost or quite often/occasionally/ rarely or never). The health status included limited in activities because of health problems during the last six months (yes/no), body mass index (BMI, weight $/$ height $^{2}, \mathrm{~kg} /$ m2) (underweight (<18.5)/normal (18.5-24.9)/overweight (25-29.9)/obese ( $\geq 30) /$ unknown), and self-reported previous diseases including hypertension (yes/no/unknown), diabetes (yes/no/unknown), heart diseases (yes/no/unknown), and stroke (yes/no/unknown). 
The weights and standing heights were measured directly by trained investigators. The BMI was categorized according to the cutoff points of the Working Group on Obesity in China [21]. The remaining variables were directly collected using the standardized questionnaire at baseline, except ventilation of the kitchen when cooking at home, which was collected only during the 2018 follow-up survey.

\section{Data analysis}

Baseline characteristics of the study population were described as the means \pm standard deviations (SDs) for the continuous variables or percentages for the categorical variables according to cooking fuel exposure. Time to cognitive impairment (event $=1$ ) was defined as the period from baseline to the earlier assessment of the MMSE. For those who died without information on cognitive impairment (event $=2$ ), the time from baseline to time of death was calculated. Censored (event $=0$ ) observations were defined as participants who did not have cognitive impairment, and the censoring time was calculated from baseline to the last assessment of the MMSE. Cox proportional hazards models were used to assess the association of biomass fuel use with cognitive impairment. The follow-up ended on the date of death or the end of the study, whichever was earlier. A sensitivity analysis was performed by fitting the different models to examine the robustness of the estimation. Model 1 was a univariate model. Basic demographic characteristics were added in model 2, including age, sex, education, residence, household income, and marital status. All of the covariates in model 3 were adjusted by adding the smoking status, drinking status, regular exercise, diet of fresh fruit and vegetables, limited in activities because of health problems during the last six months, BMI, and self-reported previous diseases based on model 2. A stratified analyses was performed by sex, education, residence, household income, smoking status, drinking status, fresh fruit, limited in activities because of health problems during the last six months and self-reported previous diseases, and the significance of interaction was tested by including a two-way interaction term in the final model. In addition, in order to test the robustness of the results: 1) Cox models for the excluded 3047 participants were performed (Supplemental Table 1); and 2) Cox models were performed for the 2933 participants in the follow-up survey after 1212 participants who died were excluded (Supplemental Table 2). A $P$ value less than 0.05 was significant. The crude incidence rates (IR) (per 100 person-years) of cognitive impairment across the categories of cooking fuels were calculated. The results were presented as pooled hazard ratios (HRs) with 95\% confidence intervals (95\% CIs). All of the analyses were performed using SPSS 26.0 and R 3.4.0.

\section{Results}

\section{Basic characteristics of the participants}

The characteristics of the 4145 participants without cognitive impairment at baseline (Table 1) had a mean (SD) age of approximately $82.69( \pm 8.90)$ years old, and $51.22 \%$ of the participants were men.

The characteristics of the study population are provided in Table 1. There were 2228 (53.75\%) clean fuel users, 59 (1.42\%) participants never cooked, 1676 (1.42\%) participants used biomass fuels for cooking, and $182(4.39 \%)$ participants used other fuels for cooking among the total of 4145 older people.

According to $\chi^{2}$ tests, some characteristics were similar across the cooking fuels groups, but differences were found according to age, sex, education level, residence, household income, marital status, regular exercise, ventilation of the kitchen when cooking at home, diet of fresh fruit or vegetables, limited in activities because of health problems during the last 6 months, body mass index (BMI), and self-reported previous diseases.

Biomass fuel users were more likely to be observed in older people who were aged 65-84 years, were male and illiterate, lived in rural areas, had lower household incomes, were unmarried, had non-regular exercise, had no ventilation when cooking, consumed fresh fruit rarely or never, consumed vegetables occasionally, were limited in activities due to health problems during the last 6 months, were underweight, and had no self-reported previous diseases.

\section{Association of biomass fuel use for cooking and the risk of cognitive impairment}

During 14,213.98 person-years of follow-up, a total of 432 incident cognitive impairment cases were observed. These included 216 cases, 10 cases, 175 cases, and 31 cases of participants that used clean fuels, never cooked, used biomass fuels, and used other fuels, respectively. Overall, the crude rate of cognitive impairment events was greater in the other three groups than in the clean fuel group (Table 2). In the unadjusted analysis, participants that reported never cooking, the use of biomass fuels, and the use of other fuels were all positively associated with an increased risk of cognitive impairment. Upon adjusting for the basic demographic characteristics, including age, sex, education, residence, household income, and marital status, the HR and 95\% CI remained significant in the biomass fuel and other fuel user groups. In the multivariable-adjusted analysis, after adjusting for all of the covariates, the association between biomass fuel use and cognitive impairment risk had a slightly diminished magnitude, but was still significant (aHR: 1.27, 95\% CI: 1.02-1.58). In addition, a greater risk of cognitive impairment was observed in the other fuel users compared with the clean fuel users (aHR: 1.82, 95\% CI: 1.23-2.69). 
Table 1 Characteristics of the study participants according to cooking fuel used at the baseline

\begin{tabular}{|c|c|c|c|c|c|}
\hline \multirow[t]{2}{*}{ Characteristics } & \multirow[t]{2}{*}{$\mathbf{N}$} & \multicolumn{4}{|c|}{ Cooking fuel } \\
\hline & & $\begin{array}{l}\text { Clean } \\
\text { fuel }\end{array}$ & $\begin{array}{l}\text { Never cooked in the } \\
\text { home }\end{array}$ & $\begin{array}{l}\text { Biomass } \\
\text { fuel }\end{array}$ & othe \\
\hline Total & 4145 & $\begin{array}{l}2228 \\
(53.75)\end{array}$ & $59(1.42)$ & $\begin{array}{l}1676 \\
(40.43)\end{array}$ & \\
\hline
\end{tabular}

\section{Demographic characteristics}

$X^{2} \quad P$

Age (years)
$65-84$
$85-104$
$\geq 105$
Sex
Male
Female
Education
No school
1 year or more
Residence
Urban
Rural

Household income CNY

$<10,000$

$10,001-30,000$

$>30,000$

Marital status

Unmarried

Married

Divorced or widowed

\section{Lifestyle habits}

Smoking status

Non-smoker

Smoker

Drinking status

Non-drinker

Drinker

Regular exercise

$$
\begin{array}{rlr}
2460 & \begin{array}{l}
1308 \\
(53.17)
\end{array} & 10(0.41) \\
1606 & 873 & 45(2.80) \\
& (54.36) & \\
79 & 47(59.49) & 4(5.06)
\end{array}
$$

$2123 \quad 1128$

(53.13)

$30(1.41)$

1100

$29(1.43)$

(54.40)

$\begin{array}{lll}2103 & 998 & 39(1.85) \\ & (47.46) & \\ 2040 & 1228 & 20(0.98) \\ & (60.20)\end{array}$

$1815 \quad 1249 \quad 26(1.43)$ (68.82)

\begin{tabular}{|c|c|c|}
\hline 2781 & $\begin{array}{l}1502 \\
(54.01)\end{array}$ & $35(1.26)$ \\
\hline & $\begin{array}{l}717 \\
(53.19)\end{array}$ & $23(1.71)$ \\
\hline
\end{tabular}

2330979

$$
\text { (42.02) }
$$

$33(1.42)$

$$
\begin{array}{rlr}
1565 & \begin{array}{l}
544 \\
(34.76)
\end{array} & 42(2.68) \\
1032 & \begin{array}{l}
568 \\
(55.04)
\end{array} & 3(0.29) \\
1548 & \begin{array}{l}
1116 \\
(72.09)
\end{array} & 14(0.90) \\
&
\end{array}
$$

$$
\begin{array}{lll}
34 & 13(38.24) & 0(0.00) \\
1952 & 1020 & 1(0.05) \\
& (52.25) & \\
2107 & 1168 & 57(2.71) \\
& (55.43) &
\end{array}
$$

$\begin{array}{rlr}2974 & \begin{array}{l}1589 \\ (53.43)\end{array} & 48(1.61) \\ 1138 & 623 & 11(0.97) \\ & (54.75) & \end{array}$

$56.798^{\mathrm{a}}<0.0001$

$1042 \quad 100$

(42.36) (4.07)

$611(38.04) \quad 77$

$23(29.11) \quad 5(6.33)$

$10.97 \quad 0.012$

$891(41.97) \quad 74$ (3.49)

785 (38.82) 108 (5.34)

$69.409<0.0001$

$960(45.65) \quad 106$ (5.04)

$716(35.10) \quad 76$

(3.73)

$325.472<0.0001$

455 (25.07) 85 (4.68)

$1221 \quad 97$

(52.40) (4.16)

$486.859^{\mathrm{a}}<0.0001$

$910(58.15) \quad 69$ (4.41)

$414(40.12) \quad 47$ (4.55)

$352(22.74) \quad 66$ (4.26)

$83.076^{\mathrm{a}}<0.0001$

$19(55.88) \quad 2(5.88)$

856 (43.85) 75 (3.84)

$781(37.07) \quad 101$ (4.79)

$3.412 \quad 0.332$

$1114 \quad 130$

(40.06) (4.67)

$557(41.32) \quad 51$

(3.78)

$4.065 \quad 0.255$

$1199 \quad 138$

(40.32) (4.64)

$461(40.51) \quad 43$ (3.78) 
Table 1 Characteristics of the study participants according to cooking fuel used the baseline (Continued)

\begin{tabular}{|c|c|c|c|c|c|c|c|}
\hline \multirow[t]{2}{*}{ Characteristics } & \multirow[t]{2}{*}{$\mathbf{N}$} & \multicolumn{4}{|c|}{ Cooking fuel } & \multirow[t]{2}{*}{$x^{2}$} & \multirow[t]{2}{*}{$P$} \\
\hline & & $\begin{array}{l}\text { Clean } \\
\text { fuel }\end{array}$ & $\begin{array}{l}\text { Never cooked in the } \\
\text { home }\end{array}$ & $\begin{array}{l}\text { Biomass } \\
\text { fuel }\end{array}$ & others & & \\
\hline Yes & 1383 & $\begin{array}{l}975 \\
(70.50)\end{array}$ & $8(0.58)$ & $328(23.72)$ & $\begin{array}{l}72 \\
(5.21)\end{array}$ & & \\
\hline No & 2668 & $\begin{array}{l}1204 \\
(45.13)\end{array}$ & $50(1.87)$ & $\begin{array}{l}1309 \\
(49.06)\end{array}$ & $\begin{array}{l}105 \\
(3.94)\end{array}$ & & \\
\hline Ventilation of the kitchen when cooking at home & & & & & & $536.392^{a}$ & $<0.0001$ \\
\hline No ventilation & 273 & $83(30.40)$ & $3(1.10)$ & $172(63.00)$ & $\begin{array}{l}15 \\
(5.49)\end{array}$ & & \\
\hline Kitchen ventilation or fan & 1061 & $\begin{array}{l}845 \\
(79.64)\end{array}$ & $9(0.85)$ & $182(17.15)$ & $\begin{array}{l}25 \\
(2.36)\end{array}$ & & \\
\hline By opening window & 1554 & $\begin{array}{l}609 \\
(39.19)\end{array}$ & $13(0.84)$ & $854(54.95)$ & $\begin{array}{l}78 \\
(5.02)\end{array}$ & & \\
\hline Unknown & 1257 & $\begin{array}{l}691 \\
(54.97)\end{array}$ & $34(2.70)$ & $468(37.23)$ & $\begin{array}{l}64 \\
(5.09)\end{array}$ & & \\
\hline Fresh fruit & & & & & & 49.406 & $<0.0001$ \\
\hline Almost or quite often & 1779 & $\begin{array}{l}1060 \\
(59.58)\end{array}$ & $30(1.69)$ & $626(35.19)$ & $\begin{array}{l}63 \\
(3.54)\end{array}$ & & \\
\hline Occasionally & 1413 & $\begin{array}{l}711 \\
(50.32)\end{array}$ & $13(0.92)$ & $620(43.88)$ & $\begin{array}{l}69 \\
(4.88)\end{array}$ & & \\
\hline Rarely or never & 943 & $\begin{array}{l}455 \\
(48.25)\end{array}$ & $15(1.59)$ & $424(44.96)$ & $\begin{array}{l}49 \\
(5.20)\end{array}$ & & \\
\hline Vegetables & & & & & & $66.510^{\mathrm{a}}$ & 0.001 \\
\hline Almost or quite often & 3758 & $\begin{array}{l}2052 \\
(54.60)\end{array}$ & $52(1.38)$ & $\begin{array}{l}1497 \\
(39.84)\end{array}$ & $\begin{array}{l}157 \\
(4.18)\end{array}$ & & \\
\hline Occasionally & 289 & $\begin{array}{l}126 \\
(43.60)\end{array}$ & $3(1.04)$ & $144(49.83)$ & $\begin{array}{l}16 \\
(5.54)\end{array}$ & & \\
\hline Rarely or never & 90 & $48(53.33)$ & $3(3.33)$ & $31(34.44)$ & $8(8.89)$ & & \\
\hline \multicolumn{8}{|l|}{ Health status } \\
\hline $\begin{array}{l}\text { Limited in activities because of health problems during the } \\
\text { last six months }\end{array}$ & & & & & & 21.041 & $<0.0001$ \\
\hline Yes & 3099 & $\begin{array}{l}1637 \\
(52.82)\end{array}$ & $33(1.06)$ & $\begin{array}{l}1300 \\
(41.95)\end{array}$ & $\begin{array}{l}129 \\
(4.16)\end{array}$ & & \\
\hline No & 1041 & $\begin{array}{l}586 \\
(56.29)\end{array}$ & $26(2.50)$ & $376(36.12)$ & $\begin{array}{l}53 \\
(5.09)\end{array}$ & & \\
\hline Body mass index $\left(\mathrm{kg} / \mathrm{m}^{2}\right)$ & & & & & & $74.429^{\mathrm{a}}$ & $<0.0001$ \\
\hline Underweight (< 18.5) & 636 & $\begin{array}{l}310 \\
(48.74)\end{array}$ & $14(2.20)$ & $276(43.40)$ & $\begin{array}{l}36 \\
(5.66)\end{array}$ & & \\
\hline Normal (18.5-23.9) & 2242 & $\begin{array}{l}1178 \\
(52.54)\end{array}$ & $20(0.89)$ & $946(42.19)$ & $\begin{array}{l}98 \\
(4.37)\end{array}$ & & \\
\hline Overweight (24-27.9) & 840 & $\begin{array}{l}493 \\
(58.69)\end{array}$ & $11(1.31)$ & $308(36.67)$ & $\begin{array}{l}28 \\
(3.33)\end{array}$ & & \\
\hline Obese ( $\geq 28)$ & 263 & $\begin{array}{l}165 \\
(62.74)\end{array}$ & $4(1.52)$ & $75(28.52)$ & $\begin{array}{l}19 \\
(7.22)\end{array}$ & & \\
\hline Unknown & 164 & $82(50.00)$ & $10(6.10)$ & $71(43.29)$ & $1(0.61)$ & & \\
\hline Hypertension & & & & & & 37.117 & $<0.0001$ \\
\hline Yes & 1413 & $\begin{array}{l}838 \\
(59.31)\end{array}$ & $17(1.20)$ & $486(34.39)$ & $\begin{array}{l}72 \\
(5.10)\end{array}$ & & \\
\hline No & 2532 & $\begin{array}{l}1283 \\
(50.67)\end{array}$ & $37(1.46)$ & $\begin{array}{l}1109 \\
(43.80)\end{array}$ & $\begin{array}{l}103 \\
(4.07)\end{array}$ & & \\
\hline Unknown & 200 & $\begin{array}{l}107 \\
(53.50)\end{array}$ & $5(2.50)$ & $81(40.50)$ & $7(3.50)$ & & \\
\hline
\end{tabular}


Table 1 Characteristics of the study participants according to cooking fuel used at the baseline (Continued)

\begin{tabular}{|c|c|c|c|c|c|c|c|}
\hline \multirow[t]{2}{*}{ Characteristics } & \multirow[t]{2}{*}{$\mathbf{N}$} & \multicolumn{4}{|c|}{ Cooking fuel } & \multirow[t]{2}{*}{$x^{2}$} & \multirow[t]{2}{*}{$P$} \\
\hline & & $\begin{array}{l}\text { Clean } \\
\text { fuel }\end{array}$ & $\begin{array}{l}\text { Never cooked in the } \\
\text { home }\end{array}$ & $\begin{array}{l}\text { Biomass } \\
\text { fuel }\end{array}$ & others & & \\
\hline Diabetes & & & & & & $26.406^{\mathrm{a}}$ & $<0.0001$ \\
\hline Yes & 243 & $\begin{array}{l}163 \\
(67.08)\end{array}$ & $1(0.41)$ & 65 (26.75) & $\begin{array}{l}14 \\
(5.76)\end{array}$ & & \\
\hline No & 3661 & $\begin{array}{l}1939 \\
(52.96)\end{array}$ & $55(1.50)$ & $\begin{array}{l}1514 \\
(41.35)\end{array}$ & $\begin{array}{l}153 \\
(4.18)\end{array}$ & & \\
\hline Unknown & 241 & $\begin{array}{l}126 \\
(52.28)\end{array}$ & $3(1.24)$ & $97(40.25)$ & $\begin{array}{l}15 \\
(6.22)\end{array}$ & & \\
\hline Heart diseases & & & & & & $38.774^{\mathrm{a}}$ & $<0.0001$ \\
\hline Yes & 524 & $\begin{array}{l}336 \\
(64.12)\end{array}$ & $6(1.15)$ & $152(29.01)$ & $\begin{array}{l}30 \\
(5.73)\end{array}$ & & \\
\hline No & 3390 & $\begin{array}{l}1772 \\
(52.27)\end{array}$ & 49 (1.45) & $\begin{array}{l}1432 \\
(42.24)\end{array}$ & $\begin{array}{l}137 \\
(4.04)\end{array}$ & & \\
\hline Unknown & 231 & $\begin{array}{l}120 \\
(51.95)\end{array}$ & $4(1.73)$ & 92 (39.83) & $\begin{array}{l}15 \\
(6.49)\end{array}$ & & \\
\hline Stroke & & & & & & $24.390^{\mathrm{a}}$ & $<0.001$ \\
\hline Yes & 313 & $\begin{array}{l}195 \\
(62.30)\end{array}$ & $2(0.64)$ & 92 (29.39) & $\begin{array}{l}24 \\
(7.67)\end{array}$ & & \\
\hline No & 3604 & $\begin{array}{l}1912 \\
(53.05)\end{array}$ & $54(1.50)$ & $\begin{array}{l}1491 \\
(41.37)\end{array}$ & $\begin{array}{l}147 \\
(4.08)\end{array}$ & & \\
\hline Unknown & 228 & $\begin{array}{l}121 \\
(53.07)\end{array}$ & $3(1.32)$ & 93 (40.79) & $\begin{array}{l}11 \\
(4.82)\end{array}$ & & \\
\hline
\end{tabular}

Notes: ${ }^{\text {a }}$ : Fisher exact test; missing data: education 2 (0.05\%), marital status 47 (1.25\%), smoking status 16 (0.39\%), drinking status 33 (0.80\%), regular exercise 94 $(2.27 \%)$, diet of fresh fruit $10(0.24 \%)$ and vegetables $8(0.12 \%)$, and limited in activities because of health problems during the last six months $5(0.12 \%)$

The analysis was stratified by sex, education, residence, household income, smoking status, drinking status, fresh fruit, limited in activities because of health problems during the last six months, and self-reported previous diseases, and the significance of an interaction was tested by including a two-way interaction term in the final model. Sex, education, household income, drinking status, fresh fruit, limited in activities because of health problems during the last six months, and self-reported previous diseases had no significant group differences. Significant group differences were found in residence and smoking status in the association of fuel use for cooking with cognitive impairment in the multivariable-adjusted model (all $P$ values for the interactions $<0.05$ ). The risk of cognitive impairment was higher among the biomass fuel users who lived in rural areas (aHR: 1.44, 95\% CI: 1.08-3.90) and never smoked (aHR: 1.33, 95\% CI: 1.04-1.71). In addition, the risk of cognitive impairment was higher among the other fuel users who lived in rural areas (aHR: 2.19, 95\% CI: 1.23-3.90) and smoked (aHR: 3.97, 95\% CI: $1.84-8.58)$ (Table 3).

Table 2 Association of cooking fuels with cognitive impairment in the univariate and multivariable models

\begin{tabular}{|c|c|c|c|c|c|c|c|}
\hline \multirow[t]{2}{*}{ Fuel } & \multirow{2}{*}{$\begin{array}{l}\mathrm{N} \text { events/ } \\
\text { Incidence } \\
\text { rate (per } \\
100 \\
\text { person- } \\
\text { years) }\end{array}$} & \multicolumn{2}{|l|}{ Model 1} & \multicolumn{2}{|l|}{ Model 2} & \multicolumn{2}{|l|}{ Model 3} \\
\hline & & $\mathrm{HR}(95 \% \mathrm{Cl})$ & $P$ & $\mathrm{HR}(95 \% \mathrm{Cl})$ & $P$ & $\mathrm{HR}(95 \% \mathrm{Cl})$ & $P$ \\
\hline Clean fuel & $216 / 2.77$ & 1 (reference) & & 1 (reference) & & 1 (reference) & \\
\hline Never cooked in the home & $10 / 5.97$ & $3.04(1.61,5.74)$ & 0.001 & $1.83(0.97,3.46)$ & 0.064 & $1.63(0.83,3.22)$ & 0.157 \\
\hline Biomass fuel & $175 / 3.11$ & $1.37(1.12,1.67)$ & 0.002 & $1.30(1.05,1.60)$ & 0.016 & $1.27(1.02,1.58)$ & 0.030 \\
\hline Others & $31 / 4.94$ & $2.11(1.45,3.08)$ & 0.000 & $1.88(1.28,2.77)$ & 0.001 & $1.82(1.23,2.69)$ & 0.003 \\
\hline
\end{tabular}

Model 1 was a univariate model. The basic demographic characteristics were added in model 2, including age, sex, education, residence, household income, and marital status. All of the covariates in the model 3 were adjusted by adding smoking status, drinking status, regular exercise, ventilation of the kitchen when cooking at home, diet of fresh fruit and vegetables, limited in activities because of health problems during the last six months, BMI, and self-reported previous diseases based on model 2 


\section{Discussion}

To our knowledge, the national longitudinal survey that examined the association of biomass fuel use for cooking with the risk of cognitive impairment among the elderly population aged 65 years and above in China has some limitations. We found that elderly people who reported that using biomass fuels for cooking had a significantly increased risk of cognitive impairment. In addition, the stratified results suggested that residence and smoking status modified the association of biomass fuel use with cognitive impairment in elderly Chinese people.

These results agreed with some studies that have reported that people who reported using biomass fuels for cooking had a significantly increased risk of cognitive impairment among adults. Krishnamoorthy et al. reported individuals who used biomass or kerosene as fuel were found to have two times more risk of having cognitive impairment according to a community-based crosssectional study that included 295 adults [22]. This cohort study of the association between biomass fuel use for cooking and cognition among older adults was believed to be lacking, and Saenz et al. found that combustion of wood or coal fuels was associated with poorer cognitive performance in 13,023 Mexican adults over aged 50 using a cross-sectional study [12]. One study reported solid fuel users (coal, biomass charcoal/wood/ straw) had worse cognitive function that was evidenced by a lower global cognition score, mental health score, and episodic memory score in the Chinese middle-aged and older populations [23]. Cao et al. found that solid cooking fuel use was associated with a greater decline in the overall cognitive score, especially for the episodic memory of middle-aged and older participants according to follow-up studies that included 8397 participants [13]. Because biomass fuel use for cooking has a higher HAP, this study primarily examined the association of biomass fuel use with cooking and cognitive impairment. Additionally, potential influencing factors that included exercise, ventilation of the kitchen when cooking at home, diet, self-reported previous diseases, and other factors were controlled for in this study compared with the aforementioned studies. Additionally, the MMSE was used in this study to assess cognitive functioning that fully evaluates orientation, registration, attention and calculation ability, recall, and language ability, not just orientation, attention, and episodic memory, compared with most aforementioned studies. Finally, it was found that biomass fuel users had a higher risk of cognitive impairment (aHR: 1.27, 95\% CI: 1.02-1.58) compared with participants who used clean fuels. Additionally, the results of this study also found the group differences due to residence and smoking status were significant based on the association of biomass fuel use with cognitive impairment. The risk of cognitive impairment was higher among the old people who lived in rural areas and never smoked. Saenz et al. also found that living in a more rural area was associated with lower scores across the cognitive function assessments [12]. This may have been because most of the participants in the rural areas reported using biomass as cooking fuels. This study was conducted in a large area that involved 23 research locations in 23 provinces in mainland China and the demographic characteristics (age, sex, education, residence, household income, and other factors), lifestyle (smoking status, drinking status, regular exercise, diet of fresh fruit and vegetables), and health status (BMI and selfreported previous diseases) were controlled for, which are related to cooking and cognitive function and affects the association of biomass fuel use with cognitive impairment. Based on these previous studies, this study further supplemented the results among elderly people and found a positive association between biomass fuel use and the risk of cognitive impairment to help develop intervention strategies focused on controlling the prevalence of cognitive impairment among elderly people in China, especially for older people living in rural areas.

The specific potential mechanism of cooking biomass fuel exposure-related cognitive impairment is unclear, but it may be linked to the PM released by the combustion of biomass fuels. The burning of biomass fuels causes high concentrations of PM [2, 3]. A large body of studies have suggested positive associations between PM and cognitive impairment. Ailshire et al. reported in 2014 [24], 2015 [25], and 2017 [26] that there was an inverse association between PM2.5 and cognitive function. Yuan et al. found $\mathrm{PM}_{10}$ was significantly associated with cognitive impairment $(\mathrm{OR}=1.09,95 \% \mathrm{CI}: 1.02,1.17)$ among Taiwanese older adults [27]. Salinas-Rodríguez et al. found that each $10 \mu \mathrm{g} / \mathrm{m} 3$ of increased ambient PM2.5 raised the odds of poorer cognitive function, including a three-word memory test and the number of valid animals named in a verbal fluency test [28]. The mechanisms involved may include brain oxidative stress, neuroinflammation, neurodegeneration [29], endothelial activation, and imbalanced autonomic nervous systems [30], all of which play key roles in the pathophysiology of brain states $[29,30]$.

According to the World Energy Outlook 2019 [1], China remains the world's largest energy consumer in all scenarios, and the retrofitting capacity to co-fire with biomass plays an important role, particularly in China. This study found the proportion of biomass fuels users was $40.43 \%$ among Chinese older people. Additionally, biomass fuel users were more likely to be observed in older people who were illiterate, lived in rural areas, and had lower household incomes. These findings suggested that cooking energy alteration are still required, especially for people who are illiterate, live in rural areas, and 
Table 3 Association of cooking fuel types with cognitive impairment stratified by participant characteristics

\begin{tabular}{|c|c|c|c|}
\hline Subgroup & $\begin{array}{l}\text { Biomass fuel } \\
\text { Adjusted } \mathrm{HR}(95 \% \mathrm{Cl})\end{array}$ & $\begin{array}{l}\text { Others } \\
\text { Adjusted HR }(95 \% \mathrm{Cl})\end{array}$ & $P$-value for interaction \\
\hline All & $1.27(1.02,1.58)$ & $1.82(1.23,2.69)$ & \\
\hline Sex & & & 0.207 \\
\hline Male & $1.26(0.87,1.83)$ & $3.37(1.72,6.60)$ & \\
\hline Female & $1.16(0.87,2.30)$ & $1.39(0.84,2.30)$ & \\
\hline Education & & & 0.604 \\
\hline No school & $1.08(0.83,1.42)$ & $1.66(1.05,2.62)$ & \\
\hline 1 year or more & $1.54(1.01,5.53)$ & $2.46(1.10,5.53)$ & \\
\hline Residence & & & 0.001 \\
\hline Urban & $0.82(0.55,1.22)$ & $1.53(0.87,2.68)$ & \\
\hline Rural & $1.44(1.08,3.90)$ & $2.19(1.23,3.90)$ & \\
\hline Household income CNY & & & 0.197 \\
\hline$<10,000$ & $1.52(1.04,2.21)$ & $2.12(1.05,4.25)$ & \\
\hline $10,001-30,000$ & $0.96(0.61,3.47)$ & $1.67(0.80,3.47)$ & \\
\hline$>30,000$ & $0.99(0.66,1.51)$ & $1.40(0.71,2.77)$ & \\
\hline Smoking status & & & 0.001 \\
\hline Non-smoker & $1.33(1.04,1.71)$ & $1.46(0.91,2.35)$ & \\
\hline Smoker & $0.66(0.38,8.58)$ & $3.97(1.84,8.58)$ & \\
\hline Drinking status & & & 0.078 \\
\hline Non-drinker & $1.19(0.93,1.53)$ & $1.64(1.06,2.53)$ & \\
\hline Drinker & $0.96(0.56,9.41)$ & $3.48(1.28,9.41)$ & \\
\hline Regular exercise & & & 0.876 \\
\hline Yes & $1.28(0.77,2.12)$ & $1.63(0.78,3.39)$ & \\
\hline No & $1.18(0.91,2.77)$ & $1.72(1.07,2.77)$ & \\
\hline Ventilation of the kitchen when cooking at home & & & 0.826 \\
\hline no ventilation & $0.74(0.32,1.69)$ & $1.46(0.42,5.04)$ & \\
\hline kitchen ventilation or fan & $0.88(0.55,3.45)$ & $1.07(0.33,3.45)$ & \\
\hline by opening window & $1.27(0.93,1.72)$ & $1.86(1.12,3.10)$ & \\
\hline unknown & $0.56(0.14,2.25)$ & $1.64(0.27,9.93)$ & \\
\hline Fresh fruit & & & 0.352 \\
\hline Almost or quite often & $0.93(0.63,1.38)$ & $1.24(0.64,2.41)$ & \\
\hline Occasionally & $1.19(0.82,4.27)$ & $2.22(1.15,4.27)$ & \\
\hline Rarely or never & $1.68(1.08,2.61)$ & $1.82(0.75,4.43)$ & \\
\hline $\begin{array}{l}\text { Limited in activities because of health problems during } \\
\text { the last six months }\end{array}$ & & & 0.449 \\
\hline Yes & $0.78(0.51,1.20)$ & $1.23(0.59,2.58)$ & \\
\hline No & $1.42(1.09,3.50)$ & $2.18(1.36,3.50)$ & \\
\hline Diabetes & & & 0.006 \\
\hline Yes & $3.33(0.73,15.19)$ & $1.09(0.18,6.50)$ & \\
\hline No & $1.18(0.93,2.70)$ & $1.76(1.15,2.70)$ & \\
\hline Unknown & $1.19(0.33,4.33)$ & $3.00(0.44,20.68)$ & \\
\hline Heart diseases & & & 0.174 \\
\hline Yes & $0.66(0.26,1.67)$ & $1.99(0.72,5.46)$ & \\
\hline No & $1.25(0.98,2.55)$ & $1.62(1.03,2.55)$ & \\
\hline Unknown & $1.02(0.26,4.03)$ & $4.20(0.48,36.67)$ & \\
\hline
\end{tabular}


Table 3 Association of cooking fuel types with cognitive impairment stratified by participant characteristics (Continued)

\begin{tabular}{llll}
\hline Subgroup & $\begin{array}{l}\text { Biomass fuel } \\
\text { Adjusted HR (95\% Cl) }\end{array}$ & $\begin{array}{l}\text { Others } \\
\text { Adjusted HR (95\% Cl) }\end{array}$ & $\begin{array}{c}P \text {-value for interaction } \\
\text { Stroke }\end{array}$ \\
Yes & $0.82(0.30,2.20)$ & $0.40(0.08,1.86)$ & 0.077 \\
No & $1.20(0.95,2.81)$ & $1.84(1.20,2.81)$ & \\
Unknown & $3.14(0.67,14.65)$ & $101.82(6.25,1659.95)$ & \\
\hline
\end{tabular}

have lower household incomes, to reduce the risk of adverse outcomes.

There are several limitations of this study. First, individual cognitive medicine use for improving cognition was not controlled for. However, the participants were free of cognitive impairments at the baseline, so this should not have altered the primary results of this prospective cohort study. Second, information regarding fuel stacking and stove types and other relevant indoor sources, such as heating and lighting, was lacking in the CLHLS survey. Hence, the effect of these factors could not be controlled for in this study. However, Cao et al. found that solid heating fuel use was associated with a greater decrease in the orientation and attention dimension [13]. Thus, this study may have overrated the effect of biomass cooking fuel on cognitive function. Third, education level has an important effect on the judgment of cognitive ability, while the elderly with lower educational levels account for a higher proportion of the older population in China. In addition, it is possible that participants with some hidden cognitive impairments could have answered inaccurately at the baseline, which may have caused a reversal causation. In order to ensure the quality of the survey, the project team had strictly and carefully trained investigators to conduct the household surveys to ensure the quality of the survey. All of the surveys were face-to-face interviews conducted at the participant's home. If participant were illiterate, investigators helped them to complete the questionnaire. Fourth, the annual assessment of cognition and fuel exposure every year from 2014 to 2018 is preferred, however, the CLHLS study is a nationwide cohort study, and it is difficult for investigators to survey many times. Finally, this study did not measure an individual's actual exposure dose of HAP from biomass fuel use, the secondary polluting fuel use that also accounts for high levels of HAP [4] and the lifetime exposure to HAP. Thus, further studies should include a more objective and exhaustive assessment of individual exposure to indoor air pollution and fuel use to confirm these findings.

\section{Conclusions}

The results of this nationwide prospective cohort study suggested that biomass fuel used for cooking was associated with cognitive impairment, as defined by MMSE, in a population-based study of elderly in China. In addition, the risk was higher among older people who lived in rural areas and never smoked. These findings suggested that altering the use of biomass fuels to green and clean energy is required to decrease the risk of cognitive impairment among Chinese older people, especially those who live in rural areas.

\section{Supplementary Information}

The online version contains supplementary material available at https://doi. org/10.1186/s12940-021-00706-1.

Additional file 1: Table S1. Association of cooking fuels with cognitive impairment in the univariate and multivariable models among excluded 3047 participants. Table S2. Association of cooking fuels with cognitive impairment in the univariate and multivariable models among 2933 participants after excluded 1212 participants who died in the follow-up survey.

\section{Abbreviations}

CLHLS: Chinese Longitudinal Healthy Longevity Survey; MMSE: Mini-Mental State Examination; HAP: Household air pollution; PM: Particulate matter; LPG: Liquefied petroleum gas; BMI: Body mass index; SDs: Standard deviations; IR: Incidence rates; HRs: Hazard ratios; Cls: Confidence intervals

\section{Acknowledgments}

We are also grateful to the CLHLS study, which provided the data in this research.

\section{Authors' contributions}

$J L$ conceptualised and designed the study, $J$ did data acquisition, MD did data curation, formal analysis, and visualization, MD and $J$ did writing original draft, $L Z$ and $J L$ did writing- reviewing and editing. The authors read and approved the final manuscript.

\section{Funding}

This study was funded by the National Key Research and Development Project of China (2019YFC1710301; 2020YFC0846300).

\section{Availability of data and materials}

Data are from the Chinese Longitudinal Healthy Longevity Survey 2011-2018 which is a public, open access repository (https://opendata.pku.edu.cn).

\section{Ethics approval and consent to participate}

The CLHLS was approved by the Ethical Review Committee of Peking University (IRB00001052-13074). All participants signed the informed consent at the time of participation. The research has been performed in accordance with the Declaration of Helsinki.

Consent for publication

Not applicable.

Competing interests

The authors declare that they have no competing interests. 


\section{Author details}

'Department of Epidemiology and Biostatistics, School of Public Health, Peking University, No.38, Xueyuan Road, Haidian District, Beijing 100191, China. ${ }^{2}$ Research Center of Clinical Epidemiology, Peking University Third Hospital, No.49 Huayuan North Road, Haidian District, Beijing 100083, China. ${ }^{3}$ Center for Primary Care \& Outcomes Research, School of Medicine, Center for Health Policy, Freeman Spogli Institute for International Studies, Stanford University, 450 Jane Stanford Way, Stanford, CA 94305-2004, USA.

Received: 3 November 2020 Accepted: 19 February 2021

Published online: 24 February 2021

\section{References}

1. International Energy Agency. World Energy Outlook 2019. 2019. https:// www.oecd-ilibrary.org/content/publication/caf32f3b-en. Accessed 6 Oct 2020.

2. Deepthi Y, Shiva Nagendra SM, Gummadi SN. Characteristics of indoor air pollution and estimation of respiratory dosage under varied fuel-type and kitchen-type in the rural areas of Telangana state in India. Sci Total Environ. 2019;650(Pt 1):616-25.

3. Dutta A, Mukherjee B, Das D, Banerjee A, Ray MR. Hypertension with elevated levels of oxidized low-density lipoprotein and anticardiolipin antibody in the circulation of premenopausal Indian women chronically exposed to biomass smoke during cooking. Indoor Air. 2011;21(2):165-76.

4. Shupler M, Hystad P, Birch A, Miller-Lionberg D, Jeronimo M, Arku RE, et al. Household and personal AIR pollution exposure measurements from 120 communities in eight countries: results from the PURE-AIR study. Lancet Planet Health. 2020;4(10):e451-62

5. Simkovich SM, Goodman D, Roa C, Crocker ME, Gianella GE, Kirenga BJ, et al. The health and social implications of household air pollution and respiratory diseases. NPJ Prim Care Respir Med. 2019;29(1):12.

6. GBD 2016 Lower Respiratory Infections Collaborators. Estimates of the global, regional, and national morbidity, mortality, and aetiologies of lower respiratory infections in 195 countries, 1990-2016: a systematic analysis for the Global Burden of Disease Study 2016. Lancet Infect Dis. 2018;18(11): 1191-210.

7. Bentayeb M, Simoni M, Norback D, Baldacci S, Maio S, Viegi G, et al. Indoor air pollution and respiratory health in the elderly. J Environ Sci Health A Tox Hazard Subst Environ Eng. 2013;48(14):1783-9.

8. Chen RY, Ho KF, Hong GB, Chuang KJ. Houseplant, indoor air pollution, and cardiovascular effects among elderly subjects in Taipei, Taiwan. Sci Total Environ. 2020;705:135770.

9. Liu J, Hou B, Ma XW, Liao H. Solid fuel use for cooking and its health effects on the elderly in rural China. Environ Sci Pollut Res Int. 2018;25(4):3669-80

10. Centers for Disease Control and Prevention. Cognitive impairment: the impact on health in lowa; 2011. https://www.cdc.gov/aging/pdf/cognitive_ impairment/cogimp_ia_final.pdf. Accessed 21 Oct 2020.

11. Yin $\mathrm{P}, \mathrm{Ma} \mathrm{Q}$, Wang L, Lin $\mathrm{P}$, Zhang M, Qi S, et al. Chronic obstructive pulmonary disease and cognitive impairment in the Chinese elderly population: a large national survey. Int J Chron Obstruct Pulmon Dis. 2016; 11:399-406.

12. Saenz JL, Wong R, Ailshire JA. Indoor air pollution and cognitive function among older Mexican adults. J Epidemiol Community Health. 2018;72(1):21-6.

13. Cao L, Zhao Z, Ji C, Xia Y. Association between solid fuel use and cognitive impairment: a cross-sectional and follow-up study in a middle-aged and older Chinese population. Environ Int. 2021;146:106251.

14. Tu L, Lv X, Yuan C, Zhang M, Fan Z, Xu X, et al. Trajectories of cognitive function and their determinants in older people: 12 years of follow-up in the Chinese longitudinal healthy longevity survey. Int Psychogeriatr. 2020; 32(6):765-75.

15. Appelberg KS, Hovda DA, Prins ML. The effects of a ketogenic diet on behavioral outcome after controlled cortical impact injury in the juvenile and adult rat. J Neurotrauma. 2009;26(4):497-506.

16. Zeng Y, Feng Q, Hesketh T, Christensen K, Vaupel JW. Survival, disabilities in activities of daily living, and physical and cognitive functioning among the oldest-old in China: a cohort study. Lancet. 2017;389(10079):1619-29.

17. Folstein MF, Folstein SE, McHugh PR. "Mini-mental state": a practical method for grading the cognitive state of patients for the clinician. J Psychiatr Res. 1975;12(3):189-98.
18. Gao MY, Yang M, Kuang WH, Qiu PY. Factors and validity analysis of minimental state examination in Chinese elderly people. Beijing Da Xue Xue Bao. 2015;47(3):443-9.

19. An R, Liu GG. Cognitive impairment and mortality among the oldest-old Chinese. Int J Geriatr Psychiatry. 2016;31(12):1345-53.

20. Chen H. Assessment of the quality of the cross-sectional data collected in the 2008-2009 wave of Chinese longitudinal healthy longevity survey. In: Yi $Z$, editor. Research on elderly population, family, health and care needs/ costs. Beijing, China: Science Press; 2010. p. 350-2.

21. Zhou B. Coorperative meta-analysis group of China obesity task force. Zhonghua Liu Xing Bing Xue Za Zhi. 2002;23(1):5-10.

22. Krishnamoorthy Y, Sarveswaran G, Sivaranjini K, Sakthivel M, Majella MG, Kumar SG. Association between indoor air pollution and cognitive impairment among adults in rural Puducherry, South India. J Neurosci Rural Pract. 2018;9(4):529-34.

23. Luo $Y$, Zhong $Y$, Pang $L$, Zhao $Y$, Liang $R$, Zheng $X$. The effects of indoor air pollution from solid fuel use on cognitive function among middle-aged and older population in China. Sci Total Environ. 2021;754:142460.

24. Ailshire JA, Crimmins EM. Fine particulate matter air pollution and cognitive function among older US adults. Am J Epidemiol. 2014;180(4):359-66.

25. Ailshire $\mathrm{JA}$, Clarke P. Fine particulate matter air pollution and cognitive function among U.S. older adults. J Gerontol B Psychol Sci Soc Sci. 2015; 70(2):322-8.

26. Ailshire J, Karraker A, Clarke P. Neighborhood social stressors, fine particulate matter air pollution, and cognitive function among older U.S. adults. Soc Sci Med. 2017;172:56-63.

27. Lo YC, Lu YC, Chang YH, Kao S, Huang HB. Air pollution exposure and cognitive function in Taiwanese older adults: a repeated measurement study. Int J Environ Res Public Health. 2019;16(16):2976.

28. Salinas-Rodríguez A, Fernández-Niño JA, Manrique-Espinoza B, MorenoBanda GL, Sosa-Ortiz AL, Qian ZM, et al. Exposure to ambient PM (2.5) concentrations and cognitive function among older Mexican adults. Environ Int. 2018;117:1-9.

29. Calderón-Garcidueñas L, Leray E, Heydarpour P, Torres-Jardón R, Reis J. Air pollution, a rising environmental risk factor for cognition neuroinflammation and neurodegeneration: the clinical impact on children and beyond. Rev Neurol (Paris). 2016;172(1):69-80.

30. Calderón-Garcidueñas L, Calderón-Garcidueñas A, Torres-Jardón R, AvilaRamírez J, Kulesza RJ, Angiulli AD. Air pollution and your brain: what do you need to know right now. Prim Health Care Res Dev. 2015;16(4):329-45.

\section{Publisher's Note}

Springer Nature remains neutral with regard to jurisdictional claims in published maps and institutional affiliations.

Ready to submit your research? Choose BMC and benefit from:

- fast, convenient online submission

- thorough peer review by experienced researchers in your field

- rapid publication on acceptance

- support for research data, including large and complex data types

- gold Open Access which fosters wider collaboration and increased citations

- maximum visibility for your research: over $100 \mathrm{M}$ website views per year

At BMC, research is always in progress.

Learn more biomedcentral.com/submissions 